\title{
As Disparidades Regionais da Neoplasia de Esôfago no Rio Grande do Sul
}

\author{
Knijnik, L.M.; Fernandes, V.F.; Fernandes, M.R.; Savegnago, D.; Mota, J.A.S.; \\ Apresentador: Leonardo Mees Knijnik
}

\section{Resumo}

Introdução: Estudos recentes apontam que diferenças socioeconômicas podem ser fatores relevantes na incidência de neoplasia de esôfago. Historicamente, o Rio Grande do Sul (RS) possui um desenvolvimento geográfico desigual, com predomínio de áreas rurais no sul do Estado e urbanas no Norte. Nos últimos anos, neoplasia de esôfago apresentou um declínio de mortalidade significativo no RS, provavelmente devido ao maior reconhecimento dos seus fatores de risco. Este estudo teve como objetivo analisar as diferenças nas taxas de mortalidade por neoplasia de esôfago entre as regiões Norte e Sul do RS e as correlacionar com indicadores socioeconômicos. Métodos: Inicialmente, dividiram-se os municípios do RS entre Norte e Sul tendo como base sua divisão nas Regionais de Saúde do RS. A seguir, foram selecionados, aleatoriamente, 13 municípios do Norte e 13 do Sul, e, posteriormente, suas taxas de mortalidade (TxM) por neoplasia esofágica de 2000 a 2009 e Índice de Desenvolvimento Humano (IDH) foram analisadas através da base dados governamental DATASUS. Resultados: Comparando as regiões Norte e Sul obteve-se diferença significativa nas TxM/100.000 habitantes $(8,4 \pm 6,1$ vs. $9,8 \pm 6,3$ $\mathrm{P}=0,022)$, respectivamente. Os homens tiveram maior TxM em relação às mulheres $(13,9 \pm 3,0$ vs. 4,4 $\pm 1,2 \mathrm{P}<0,001)$. O IDH médio dos múnicipios da região Norte e Sul foi, respectivamente, $0,8123 \pm 0,027$ e $0,7817 \pm 0,024(\mathrm{p}=0,0064)$. Houve correlação entre as TxM e IDH (Pearson $=-0,488$ $\mathrm{P}=0,011)$. Conclusões: Nosso estudo revelou uma maior ocorrência de óbitos por neoplasia esofágica no Sul em relação ao Norte do RS, possivelmente por menor desenvolvimento socioeconômico regional. Estudos futuros são necessários para correlacionar este achado com outros de fatores de risco como tabagismo e averiguar a causa da maior TxM por câncer esofágico no Sul do RS.

\section{Referência:}

Knijnik, L.M.; Fernandes, V.F.; Fernandes, M.R.; Savegnago, D.; Mota, J.A.S.;. As Disparidades Regionais da Neoplasia de Esôfago no Rio Grande do Sul. In: II Congresso Brasileiro de Medicina Hospitalar - II CBMH [= Blucher Medical Proceedings, vol.1, num.5] São Paulo: Editora Blucher, 2014. p.67

DOI 10.5151/medpro-II-cbmh-064 